\title{
A behavioral medicine intervention for older women living alone with chronic pain - a feasibility study
}

This article was published in the following Dove Press journal:

Clinical Interventions in Aging

18 August 2014

Number of times this article has been viewed

\author{
Sara Cederbom ${ }^{1,2}$ \\ Elisabeth Rydwik ${ }^{2,3}$ \\ Anne Söderlund ${ }^{2}$ \\ Eva Denison ${ }^{2}$ \\ Kerstin Frändin' \\ Petra von Heideken \\ Wågert ${ }^{2}$
}

'Department of Neurobiology, Care Sciences and Society, Division of Physiotherapy, Karolinska Institutet, Huddinge, ${ }^{2}$ School of Health, Care and Social Welfare, Mälardalen University, Eskilstuna, Vasteras, ${ }^{3}$ Research and Development Unit, Jakobsbergs Hospital, Stockholm County Council, Järfälla, Sweden
Correspondence: Sara Cederbom School of Health, Care and Social Welfare, Mälardalen University, Box 325, Eskilstuna 63। 05, Sweden

Tel +46 I6 I53 277

Email sara.cederbom@mdh.se
Background: To be an older woman, live alone, have chronic pain, and be dependent on support are all factors that may have an impact on daily life. One way to promote ability in everyday activities in people with pain-related conditions is to use individualized, integrated behavioral medicine in physical therapy interventions. How this kind of intervention works for older women living alone at home, with chronic pain, and dependent on formal care to manage their everyday lives has not been studied. The aim was to explore the feasibility of a study and to evaluate an individually tailored integrated behavioral medicine in physical therapy intervention for the target group of women.

Materials and methods: The study was a 12-week randomized trial with two-group design. Primary effect outcomes were pain-related disability and morale. Secondary effect outcomes focused on pain-related beliefs, self-efficacy for exercise, concerns of falling, physical activity, and physical performance.

Results: In total, 23 women agreed to participate in the study and 16 women completed the intervention. The results showed that the behavioral medicine in physical therapy intervention was feasible. No effects were seen on the primary effect outcomes. The experimental intervention seemed to improve the level of physical activity and self-efficacy for exercise. Some of the participants in both groups perceived that they could manage their everyday life in a better way after participation in the study.

Conclusion: Results from this study are encouraging, but the study procedure and interventions have to be refined and tested in a larger feasibility study to be able to evaluate the effects of these kinds of interventions on pain-related disability, pain-related beliefs, self-efficacy in everyday activities, and morale in the target group. Further research is also needed to refine and evaluate effects from individualized reminder routines, support to collect self-report data, safety procedures for balance training, and training of personnel to enhance self-efficacy.

Keywords: biopsychosocial model, community-dwelling, elderly, female, exercise intervention, physical therapy

\section{Introduction}

Older women living alone are an increasing group in society, and a significant number of this group live with chronic pain. ${ }^{1,2}$ To live with chronic pain can affect a person's whole life, eg, by causing pain-related disability, social isolation, or lower quality of life. Such pain-related problems have been shown to be more common among older women than older men. 3,4

Pain-related beliefs, such as affective distress ${ }^{3}$ and pain-catastrophizing thoughts, ${ }^{5}$ are psychosocial factors that can have a negative impact on pain among older adults. Self-efficacy seems to be a crucial factor in the development of pain-related disability 
and pain-related beliefs. ${ }^{6}$ Self-efficacy can be explained as a person's beliefs in his or her confidence to perform a specific activity. ${ }^{7,8}$ Results from a recently published study ${ }^{9}$ focusing on older women living alone at home with chronic pain showed that the pain limited the women's everyday life, and that they generally had a low physical activity level. They also reported low levels of affective distress, catastrophizing thoughts, and self-efficacy in various activities, high levels of fear of movement, low degrees of pain-related disability, and low morale. Morale is used synonymously with well-being, quality of life, and life satisfaction. ${ }^{10,11}$ Living in ordinary housing, absence of depressive symptoms, and not feeling lonely are factors positively associated with high morale among the oldest age-groups. ${ }^{12}$ Previous research has also shown that chronic pain in the oldest age-groups was associated with low levels of morale. ${ }^{10}$

As pain is a complex and multidimensional experience, health care professionals need to be aware of how the multidimensional pain experience affects an older person's life. The goal for health care professionals is to assure high quality of life, as well as maximum functional ability for older people living with pain. ${ }^{13}$ Performance of everyday activities is fundamental for older people's continued independence and quality of life. ${ }^{13}$

Evidence-based guidelines for assessment and treatment of chronic pain in community-dwelling older people receiving formal help from the community are emerging. ${ }^{14}$ One way to promote and maintain ability in everyday activities in people with pain-related conditions is to use individualized, integrated behavioral medicine in physical therapy interventions. ${ }^{15-18}$ Such interventions are based on the biopsychosocial model, and focus on how a person's thoughts, behavior, and environment may influence rehabilitation. ${ }^{16,19,20}$ These kinds of interventions have been shown to be beneficial for various pain conditions in middle-aged people. ${ }^{15,17,18}$

Behavioral medicine interventions are often combined with physical activity. ${ }^{19}$ The American Geriatric Society has stated that physical exercise should be part of the care for older adults with chronic pain. ${ }^{21}$ Thomas et al showed that physical exercise and rehabilitation are of importance to reduce limitation and participation restriction for those older adults who are having difficulty coping with pain. ${ }^{22}$ It has also been shown that older adults living with chronic pain are less physically active than those without pain. ${ }^{23}$ However, changing a person's behavior to become, for example, more physically active depends partly on available support. ${ }^{24}$

How evidence-based behavioral medicine interventions work for this specific target group has previously not been studied. This is the first study of its kind, as far as we know, and thus we chose to conduct a feasibility study. Our aim was to explore feasibility and to evaluate an individually tailored integrated behavioral medicine in physical therapy intervention for older women living alone at home with chronic pain and dependent on formal care to manage their everyday life.

\section{Materials and methods}

A 12-week randomized trial with a two-group design was used. The study included measurements pre- and postintervention and at 12-week follow-up (referred to as baseline, follow-up 1, and follow-up 2).

\section{Setting and participants}

This study is part of a larger research project about older women, living alone at home, living with chronic pain, and dependent on formal care to manage their everyday life. The study was carried out in a municipality in central Sweden.

Older women aged 65 years or more, living alone in ordinary housing in the central part of the municipality, receiving home-help services at least once a week with individual care and/or with housekeeping activities were invited to participate in the study $(\mathrm{n}=248)$. Further inclusion criteria were: musculoskeletal pain for 3 months or longer, ability to walk independently with or without a walking aid indoors, ability to understand and speak Swedish, and sufficient cognitive capacity, ie, 24 points or more on the Mini-Mental Statement Examination (MMSE). ${ }^{25}$ Exclusion criteria were women who regularly visited a physical therapist and had ongoing physical therapy treatment for injury/illness, were in a palliative stage of treatment, or had heart failure in the past 3 months.

Participants were recruited from an earlier survey study. ${ }^{9}$ Since only ten participants agreed to participate, further recruitment was made $(n=188)$. See Figure 1 for a description of the recruitment of participants. All the women received a letter with information about the study. The first author then contacted the women by phone. For those who gave their informed consent $(n=23)$, all inclusion criteria were checked over the phone, except for the MMSE score, and an appointment for an interview was agreed on.

As the present study was a feasibility study, a maximum of 30 participants were to be recruited. The sample size was based on a recommendation of an appropriate sample size of 30 participants for feasibility studies. ${ }^{26}$ Data collection was performed over a period of 13 months. 


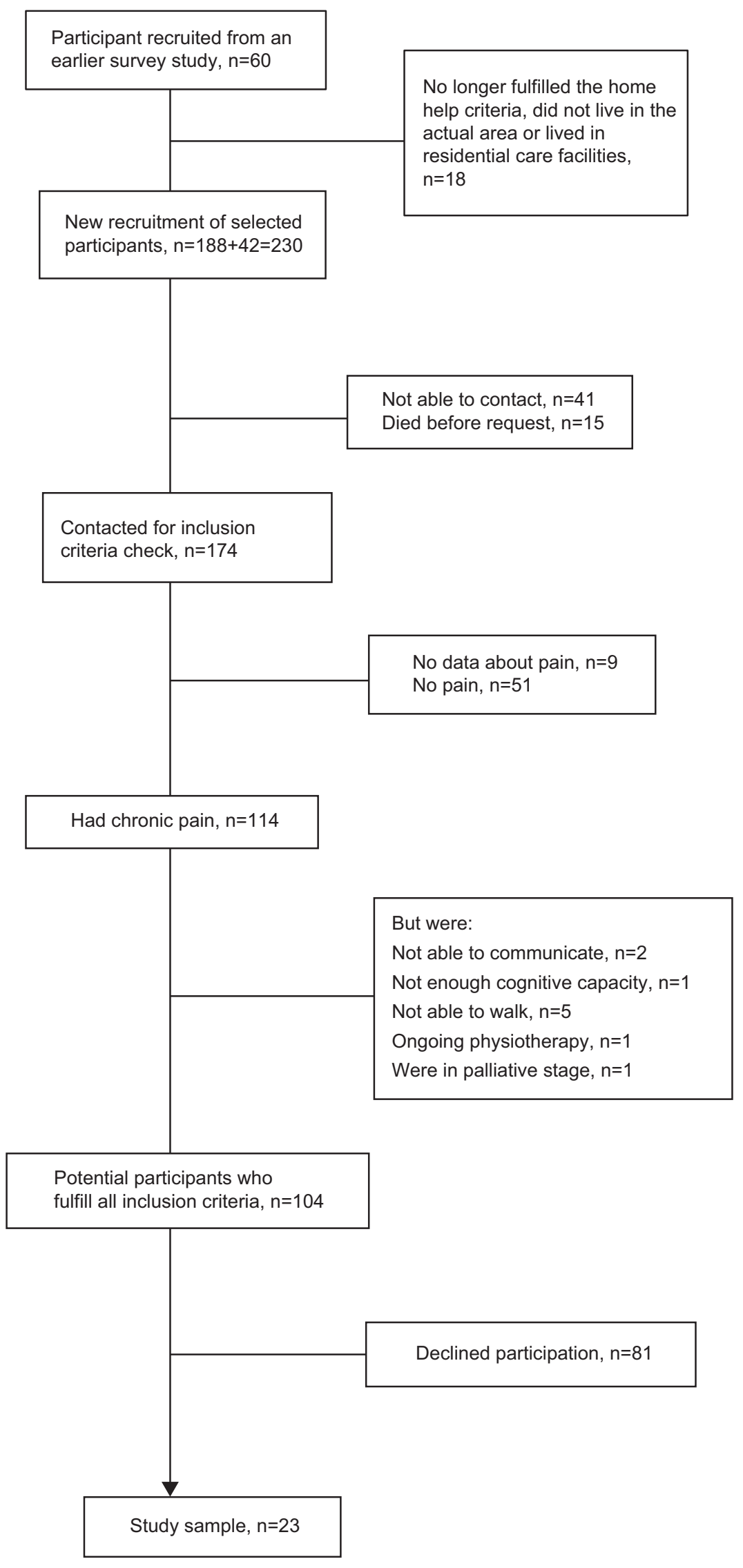

Figure I Flow chart of study sample. 


\section{Procedure}

The intervention and all assessments were performed in the participants' homes. Before the baseline assessment started, the MMSE score was checked. If a person scored 24 or more on the assessment, she was included in the study, but if not, she received both oral and written information that her participation in the study was finished due to the low score on the MMSE. All assessments used in the study were administered by the first author and conducted in a standardized way, which means that all assessments were performed in the same order for all participants.

\section{Randomization}

The randomization sequence was computer-generated and conducted by the fourth author, who was not involved in the data collection of the study. Group allocation was concealed using opaque, sealed envelopes with study identification numbers in sequential order. The participants were randomized to either the experimental or comparison group after baseline assessment.

\section{Interventions}

Both groups received eight visits by a physical therapist (first author) during intervention weeks 1, 2, 3, 4, 6, 8, 10, and 12 . Both the physical therapist and the participants were aware of which group the woman belonged to. All women received general advice about physical activity based on recommendations for physical activity for older persons, 65 years and over, ${ }^{27,28}$ from the World Health Organization and the American College of Sports Medicine. The advice was to be physically active, eg, take a walk, for at least 30 minutes a day, which could be divided into 10-minute sessions. The advice also included examples of different kinds of activities, ie, walking both indoors and outdoors, chair stand exercise, balance training, stair climbing, and sit-ups. The women also received information about known benefits of physical activity in relation to pain problems and activity. ${ }^{21,27,28}$

Adherence to the recommendation about physical activity was set for the women to be physically active at least 30 minutes in 5 of 7 days. This was monitored by an activity diary. The participants were instructed to fill in all physical activities they performed every day as well as the duration and intensity of each activity. The diaries were collected at each visit and new ones were distributed.

\section{Experimental group}

The individualized intervention was based on integrated behavioral medicine and physical therapy principles. ${ }^{15-17}$ An important component of the intervention was analysis of each person's physical and psychological characteristics, as well as social and physical environmental factors, and how these factors affected the person's ability to perform specific everyday activities that they had difficulties in managing and/or performing. A basic idea in the intervention was that if a person acquires skills to manage a specific activity, these skills can be systematically generalized to more activities or situations. ${ }^{16}$ The content of the intervention is described in Table 1. The women were instructed to practice their specific exercises according to the goal behavior at least 5 of 7 days.

Participants were reminded by home-help services staff to do their exercise(s) and fill out the activity diary, with the goal to reinforce the desired behavior. The women were reminded once a day or as often as the women had help from the home-help services. The goal was to attain at least $80 \%$ of possible reminders from the home-help services. The home-help service staff received information at two different times about their participation in the study before the study started. They were also reminded via phone by the physical therapist once a week during the intervention period. The reminder was also put on the daily schedule for the staff. The staff registered their reminder in a diary that was kept in each participant's home.

\section{Comparison group}

During the first visit, the women received advice regarding physical activity. The remaining visits were made to collect the diary and leave a new one. No intervention-related discussions took place.

\section{Study assessments}

Data regarding age, number of years living with chronic pain, support from relatives, and whether the participants were able to go outdoors by themselves were collected by interview with questions that were constructed for the study. Data about support from home-help services, diagnoses, and prescribed medication were collected from the municipality data register and from medical charts. Support from homehelp services could include help with personal activities, eg, hygiene, getting dressed, showering, or various kinds of housekeeping activities.

\section{Feasibility of the study}

Reasons for exclusion and decline were documented during inclusion of participants and for dropouts. The feasibility of the study procedure and intervention protocol was recorded using field notes during the intervention. The field notes included comments about time needed to collect the data, 
Table I Description of the content in the intervention for the experimental group

\begin{tabular}{|c|c|c|}
\hline Visit & Intervention components & Contents \\
\hline \multirow[t]{5}{*}{ I } & Identification of a problematic everyday & Observation of the performance of the goal behavior. Identification of \\
\hline & activity. Choice of goal behavior & physical, psychological and environmental factors that can have importance \\
\hline & & for the goal behavior. Identification of short and long term consequences \\
\hline & & the woman perceived from the behavior. \\
\hline & Advice about physical activity & $\begin{array}{l}\text { Oral and written information about the advice and instruction on how to } \\
\text { fill in the activity diary. }\end{array}$ \\
\hline \multirow[t]{5}{*}{2} & $\begin{array}{l}\text { Individual Functional Behavioral Analysis } \\
\text { (FBA) }\end{array}$ & $\begin{array}{l}\text { Summary and analysis of collected information. Formulation of hypotheses } \\
\text { regarding the relations between the physical, psychological, and }\end{array}$ \\
\hline & & $\begin{array}{l}\text { environmental factors, the goal behavior and the consequences of the goal } \\
\text { behavior. }\end{array}$ \\
\hline & Specific, Measurable, Activity-based, Realistic & Discussion and agreement about performance and dosage of training \\
\hline & and Time-delimited (SMART) goal-setting & according to the SMART goal setting. \\
\hline & and intervention planning & \\
\hline $3-5$ & Basic skills acquisition & $\begin{array}{l}\text { Training of basic physical, psychological and organizational skills relevant to } \\
\text { the goal behavior. }\end{array}$ \\
\hline \multirow[t]{6}{*}{$6-8$} & Applied skills acquisition & Training to apply basic skills adequately in the goal behavior. \\
\hline & Generalization & $\begin{array}{l}\text { Application of basic and applied skills in other behaviors starting with } \\
\text { subsequent activity goals. }\end{array}$ \\
\hline & Maintenance and relapse prevention & Discussion about how the woman could be able to maintain her new \\
\hline & & behavior. Discussion of problem solving strategies, how she could prevent \\
\hline & & and deal with new activity problems that may arise related to the goal \\
\hline & & behavior and in relation to be physically active. \\
\hline
\end{tabular}

time spent during the intervention visits, adherence to study procedure and intervention protocol, and issues that were recognized in relation to study procedure and intervention protocols, eg, any problems with filling out activity diaries and problems with exercise programs. Consumer questions were asked to assess how satisfied the women had been with the intervention, their rating of physical activity level, how they perceived their ability to manage their everyday life after participation in the study, and if they felt they had learned anything by the intervention. The response alternatives for how satisfied the women had been with the intervention were not satisfied at all, a little satisfied, rather satisfied, and very satisfied. The response alternatives for the questions about physical activity level and management of everyday life were much better, better, no difference, lower, and much lower. The question about what they had learned was an open-ended question.

All assessments were assessed at baseline, follow-up 1, and follow-up 2, except for the consumer questions regarding how satisfied participants had been with the intervention, which was assessed only at follow-up 1 .

\section{Primary effect outcomes Pain-related disability}

Pain-related disability was assessed with a slightly modified version of the Chronic Pain Grade Questionnaire
(CPGQ). ${ }^{29}$ In the original version, ${ }^{30}$ the questions assessed pain-related disability during the past 6 months, and in this modified version pain-related disability was assessed during the past 4 weeks. The instrument consists of seven items. Six of the questions have an 11-grade response format. The first three items rate pain, where the response format is $0=$ no pain and $10=$ worst imaginable pain, which is based on a calculation formula that gives a total score for pain intensity between 0 and 100 . The next three items rate pain-related disability in three specific activities, where $0=$ not at all and $10=$ impossible to perform the activities, which is also calculated with a formula giving a total score for disability between 0 and 100 . The last item concerns how many days the person could not do what they would usually do due to pain during the past month, with a total score between 0 and 31 . Based on the total score, persons with chronic pain are classified into one of four hierarchical categories according to pain severity and interference: grade I, low disability, low pain intensity; grade II, low disability, high pain intensity; grade III, high disability, moderately limiting pain; and grade IV, high disability, severely limiting pain. ${ }^{31}$ The CPGQ is a reliable (Cronbach's $\alpha=0.91$ ) and valid measurement, and has been used in population-based studies in ages 18-75 years. ${ }^{31,32}$ Cronbach's $\alpha$ for the CPGQ in the current sample was 0.71 . 


\section{Morale}

Morale was assessed with the 17-item Swedish version of the Philadelphia Geriatric Center Morale Scale (PGCMS). ${ }^{11,33}$ The response format is yes/no. Each answer indicating high morale is scored 1 point, and answers indicating low morale or if the person was not able to answer are scored 0 points. The total score varies between 0 and 17, where scores 13-17 indicate high morale, 10-12 middle range, and 0-9 low morale. ${ }^{9}$ The Swedish version of the PGCMS has shown satisfactory interrater reliability $(r=0.86)$ in a geriatric clinic sample. ${ }^{10}$ Cronbach's $\alpha$ for the PGCMS in the current sample was 0.76 .

\section{Secondary effect outcomes}

\section{Pain-related affective distress}

Pain-related affective distress was assessed with the Multidimensional Pain Inventory, brief Swedish version (MPI-S). ${ }^{34}$ The scale consists of eight items, covering four dimensions: pain severity, interference, life control, and affective distress (the only dimensions that are used in this study). The response format is $0-6(0=$ no/not at all, and $6=$ yes/very much $)$. Higher scores indicate higher pain-related affective distress. The MPI-S has been shown to be reliable for older persons, with Cronbach's $\alpha$ varying between 0.59 and $0.82 .{ }^{34}$

\section{Pain-related beliefs}

The following parts from the Coping Strategies Questionnaire $(\mathrm{CSQ})^{35}$ were used for assessing pain-related beliefs. The catastrophizing (CAT) subscale consists of six items assessing catastrophic thoughts, where subjects indicate how often they experience such thoughts. The response format is $0-6$, where $0=$ never think that way and $6=$ always think that way. The maximum score for the CAT subscale is 36 and indicates more catastrophizing thoughts. The CAT subscale has shown satisfactory-to-good reliability (Cronbach's $\alpha=0.85-0.86)^{6}$ and good validity. ${ }^{6,36}$ Cronbach's $\alpha$ for the CAT subscale in the current sample was 0.91 .

Two independent items from the CSQ - control over pain and ability to decrease pain - were used with a response scale from 0 to 6 , where $0=$ little control/ability and $6=$ very high control/ability. Low scores indicate low control over pain and low ability to decrease pain. The Swedish version of the CSQ has shown fair-to-good internal consistency. ${ }^{35}$

\section{Falls efficacy}

Falls efficacy was assessed by the Falls Efficacy Scale International, ${ }^{37}$ Swedish version (FES-I $\left.[\mathrm{S}]\right) .{ }^{38}$ The FES-I(S) assesses concern about falling in physical and social activities. The FES-I(S) consists of 16 items. The response format is 1-4: not at all, a little, quite a bit, and very much. The maximum score is 68 and indicates high concern about falling. The FES-I(S) has been shown to have high internal reliability (Cronbach's $\alpha=0.95$ ) for persons aged 50-85 years. ${ }^{38}$ Cronbach's $\alpha$ for the FES-I (S) in the current sample was 0.91 .

\section{Exercise self-efficacy}

Self-efficacy for exercise was assessed by the Self-Efficacy for Exercise scale, ${ }^{39}$ Swedish Version (SEE-SV). ${ }^{40}$ The overall question in the SEE questionnaire is

How confident are you right now that you could exercise three times per week for 20 minutes if, eg, the weather bothered you, you felt pain when you exercised, and you did not enjoy it?,

for nine different items. An 11-grade numeric rating scale from 0 to 10 was used, where $0=$ not confident and $10=$ very confident. The maximum score is 90 , indicating high self-efficacy. The SEE-SV scale has been shown to be reliable (Cronbach's $\alpha=0.92$ ) and have satisfactory validity for older people. ${ }^{41} \mathrm{Cron}$ bach's $\alpha$ in the SEE-SV scale in the current sample was 0.89 .

\section{Level of physical activity}

Level of physical activity was estimated for summer and winter seasons according to a 6 -grade scale. The scale, ranging from hardly any physical activity (level 1 ) to hard exercise several times a week (level 6), includes household activities. ${ }^{42,43}$ The scale has been shown to be valid for older people. ${ }^{44}$

\section{0-second chair stand test}

A 30-second chair stand test was conducted, and the number of stands was recorded. ${ }^{45,46}$ Subjects were instructed to rise from a chair (height 44-46 cm) with their arms folded over their chest, as many times as possible in 30 seconds. They were instructed to stand fully erect and sit down properly each time. The 30 -second chair stand test has been shown to be reliable (test-retest, $r=0.89$ ) for older communitydwelling people. ${ }^{46}$

\section{4-meter gait test}

Time taken to walk $2.4 \mathrm{~m}$ ( 8 feet) was tested at fastest speed. ${ }^{47,48}$ Participants used their walking aids and the footwear they normally used indoors. The distance was marked on the floor with green tape, and the participant stood just behind the starting line before the test. A digital stopwatch was started 
when the participant started to walk, and stopped when the first foot crossed the finishing line. Participants were asked to walk the distance safely, past the finishing line. The walking test has been shown to be reliable for older people. ${ }^{47}$

\section{Assessment of intensity of physical activity and assessment of mood}

Participants in both groups were instructed to rate the intensity of the physical activity they performed in the activity diaries. The intensity was rated on the Borg Category Ratio scale $(\mathrm{CR}-10),{ }^{49}$ where $0=$ nothing at all and $10=$ very, very high. The women in the experimental group also rated their mood during performance of physical activity and when they performed their goal behavior. This was assessed with an 11 -grade numeric rating scale, ${ }^{50}$ where $0=\mathrm{I}$ feel sad, $5=\mathrm{I}$ feel neither sad nor happy, and 10=I feel happy/great/excellent.

\section{Ethics}

Each participant was given oral and written information about the study. They were reassured that their participation was entirely voluntary and that they could withdraw from the study at any time before or after signing an informed consent form. The participants also gave their consent for the first author to assess their medical charts. The project was approved by the Regional Ethics Review Board in Uppsala, Sweden, DNR 2013/157.

\section{Data analysis}

SPSS version 20 (IBM Corporation, Armonk, NY, USA) was used for the statistical analysis of data. Variables were described by frequencies, means, standard deviation, median, and range. The independent $t$-test was used to analyze age differences between participants and those who declined participation. Differences between groups were assessed with $\chi^{2}$ tests for categorical data, while the Mann-Whitney $U$-test was used for ordinal data. With regard to the Mann-Whitney $U$-test, the analyses were based on changes in scores from baseline to follow-up 1 and from follow-up 1 to follow-up 2 . Within-group differences were analyzed with the Wilcoxon signed-rank test. Cronbach's $\alpha$ was calculated for the CPGQ, CAT subscale, and SEE-SV scale, which have only to a lesser extent been used among the older population. No imputation of missing data, except for in the SEE-SV scale, where the missing data were replaced with the number zero, or intention-to-treat analyses were used due to the exploratory nature of the study.

There were a few missing data in background information, SEE-SV scale, affective distress, and the 2.4 meter gait test. There was a high degree of missing data regarding ratings on the Borg CR-10 scale and for participants' mood ratings during activities in the activity diaries. Because of the amount of missing data regarding ratings on the Borg CR-10 scale and participants' mood, these variables were not analyzed. The analysis of baseline characteristics included all participants $(n=23)$, but analysis over time included only those who had completed the study $(n=17)$ between baseline and follow-up 1 and between follow-up 1 and follow-up 2 $(n=16)$.

\section{Results \\ Feasibility of the study}

Of 104 eligible women, 23 agreed to participate. In total, 16 women $(69 \%)$ - nine in the experimental group and seven in the comparison group - completed the intervention. The most common reasons for declining participation were lack of energy/too tired $(n=15)$, not interested $(n=9)$, had no time, felt that they already were physically active, or could not fill in diaries $(n=9)$, or that the women did not think that anything could help $(n=4)$. No significant age differences were found between those who agreed to participate and those who declined.

In total, seven women dropped out: three in the experimental group and four in the comparison group. In the experimental group, the first participant dropped out directly after the start of the intervention because she had recently had a stroke and felt too tired to participate; the second withdrew after intervention week 5 because of health problems, lack of energy, and problems filling out the activity diary because of vision impairment; the third withdrew just before follow-up 2 because she had recently been hospitalized. In the comparison group, one woman withdrew before the start of the intervention because she wanted to try another kind of treatment, and three participants were hospitalized: one before the start of the intervention, one after intervention week 1 and one after intervention week 4.

No significant differences at baseline between the experimental and comparison group in terms of demographic data or in the included assessments were found. Further, no significant differences between dropouts and remaining participants regarding age, MMSE score, number of hours of home-help service per week, number of years with pain, number of diseases, pain intensity, disability score, disability grade, or morale were found. More detailed baseline characteristics of the sample are reported in Table 2 and Table 3.

The study procedure was found to be feasible, but some issues were found along the way. The interventions were 
Table 2 Baseline characteristics for the participants

\begin{tabular}{|c|c|c|c|}
\hline Baseline characteristics & $\begin{array}{l}\text { Experimental } \\
\text { group }(n=\mid 2)\end{array}$ & $\begin{array}{l}\text { Comparison } \\
\text { group }(n=I I)\end{array}$ & $P$-value \\
\hline Age, years, mean (SD) & $84.5(6.7)$ & $83.8(4.9)$ & 0.57 \\
\hline $\mathrm{MMSE},{ }^{25}$ mean $(\mathrm{SD})$ & $27.7(1.3)$ & $27(1.3)$ & 0.22 \\
\hline Years with pain, mean (SD) & $28.8(21.8)$ & $26(22.1)(n=10)$ & 0.21 \\
\hline Help from relatives, \%, yes (no) & $75(25)$ & $72(18)(n=10)$ & 0.78 \\
\hline $\begin{array}{l}\text { Home-help services, number of visits } \\
\text { per week, mean (SD) }\end{array}$ & $17.3(6.7)$ & $15.6(9.5)(n=10)$ & 0.56 \\
\hline Get outdoors by themselves, \%, yes (no) & $58(42)$ & $27(63)(n=10)$ & 0.18 \\
\hline Number of diseases, mean (SD) & $3.6(1.2)$ & $3.1(1.8)$ & 0.06 \\
\hline Number of medications, mean (SD) & $8.3(4.0)$ & $5.2(1.7)$ & 0.65 \\
\hline $\begin{array}{l}\text { Number of prescribed/nonprescribed } \\
\text { pain medications, mean (SD) }\end{array}$ & $0.57 / 0.99(0.78 / 0.35)$ & $0.29 / 1(0.49 / 0)$ & $0.96 / 0.56$ \\
\hline
\end{tabular}

Abbreviations: SD, standard deviation; MMSE, Mini-Mental State Examination.

found to be feasible in a home environment. The baseline and follow-up assessments took about 45-60 minutes, the same as the average visits in the experimental group. The visits in the comparison group took no more than 10 minutes. The information given to the home-help services staff about the study took about 20 minutes, and the telephone reminder took on average 2 minutes.

Difficulties recognized in field notes regarding the intervention in the experimental group were to find a goal behavior in some cases, individual adaptation regarding balance training, and to enable outdoor training. Issues that were recognized in both groups were filling out the activity diaries because of, eg, vision impairment, understanding how to fill it out, or remembering to fill in all variables. Some of the women expressed that it was a long time period to fill out the diary for 12 weeks. With regard to assessments, the SEE-SV scale was reported to be difficult for participants to answer because the assessment does not define what is meant by "exercise", and some women expressed that they were not able to exercise three times a week for 20 minutes, which the items in the SEE-SV scale are based on.

The results of the consumer questions showed that nine women in the experimental group were satisfied or very satisfied with the intervention they had received and one woman was not satisfied at all. Overall, the women were satisfied with the recommendations they received about physical

Table 3 Baseline assessments for the participants, presented as means (standard deviation)

\begin{tabular}{|c|c|c|c|}
\hline Assessment & $\begin{array}{l}\text { Experimental } \\
\text { group }(n=12)\end{array}$ & $\begin{array}{l}\text { Comparison } \\
\text { group }(n=I I)\end{array}$ & $P$-value \\
\hline Pain intensity, CPGQ ${ }^{29,30}(0-100 *)$ & 46.1 (30.9) & $50.6(19.7)$ & 0.93 \\
\hline Disability score, CPGQ ${ }^{29,30}(0-100 *)$ & $30.3(20.2)$ & I5.9 (I8.5) & 0.07 \\
\hline Number of nongrade, CPGQ 29,30 & I & & 0.52 (total grade score) \\
\hline Grade I, n & 5 & 7 & \\
\hline Grade II, n & 4 & 4 & \\
\hline Grade III, n & 0 & 0 & \\
\hline Grade IV, n & 2 & 0 & \\
\hline Morale, PGCMS ${ }^{11,33}\left(0-17^{*}\right)$ & $9.0(3.6)$ & $10.1(3.9)$ & 0.49 \\
\hline Affective distress, MPI-S $\mathrm{S}^{34}(0-6 *)$ & $2.5(2.5)$ & $0.5(\mathrm{I})$ & 0.06 \\
\hline CAT, CSQ $^{35,36}\left(0-36^{*}\right)$ & $8.6(11.1)$ & $5.5(5.5)$ & 0.66 \\
\hline Control over pain, $\mathrm{CSQ}^{35,36}(0-6 *)$ & $2.2(1.6)$ & $1.6(2.1)$ & 0.39 \\
\hline Ability to decrease pain, $\mathrm{CSQ}^{35,36}(0-6 *)$ & $1.4(1.8)$ & $0.8( \pm I .4)$ & 0.42 \\
\hline FES-I(S) $)^{37,38}\left(0-68^{*}\right)$ & $4 I .1(11.2)$ & $38.5(9.0)$ & 0.74 \\
\hline SEE-SV ${ }^{39,40}(0-90 *)$ & $46(28.4)$ & $25.6(26.4)$ & 0.16 \\
\hline Physical activity scale ${ }^{43,44}\left(\mathrm{I}-6^{*}\right)$ & $2.4(0.5 \mathrm{I})$ & $2.4(0.52)$ & 0.86 \\
\hline 30 -second chair stand test, ${ }^{46} \mathrm{n}$ & $3.5(3.8)$ & $1.6(2.6)$ & 0.19 \\
\hline $2.4 \mathrm{~m}$ gait test $\mathrm{t}^{48}$, seconds & $12.2(20.1)$ & $7.5(2.9)$ & 0.32 \\
\hline
\end{tabular}

Note: Data are expressed as mean (standard deviation). *Minimum-maximum scores of the assessment.

Abbreviations: CPGQ, Chronic Pain Grade Questionnaire; nongrade, persons who not get any scores on CPGQ; PGCMS, Philadelphia Geriatric Center Morale Scale; MPI-S, Multidimensional Pain Inventory, brief screening version, Swedish; CAT, catastrophizing thoughts; CSQ, Coping Strategy Questionnaire; FES-I(S), Falls Efficacy Scale, International, Swedish; SEE-SV, Self-Efficacy for Exercise scale, Swedish Version. 
activity; ten women were very satisfied, six of them were rather not, and one did not know. The activity diary was rated to have been a support to perform physical activity according to the recommendations, for 12 of the women, to a rather high degree to very high degree. The remaining women $(n=5)$ thought that the activity diaries were not a support or only to a lesser degree. Results of the consumer questions regarding physical activity and management of everyday life are presented in Table 4 .

With regard to the consumer question about what they had learned during the intervention, all participants expressed that they were more aware of the importance of being physically active than before the start of the intervention. According to field notes that were recorded, the majority of the women gave positive impressions of the intervention regardless of what group they belonged to.

\section{Adherence to the intervention protocol}

All the women had been physically active at least 5 of 7 days, but the women in the comparison group had on average not reached the goal to be physically active for at least 30 minutes, while the participants in the experimental group did.

The experimental group was on average reminded by the home-help service staff $55 \%$ (range $0 \%-100 \%$ ) of the times they should have been reminded. Seven of nine women rated the reminder as not important at all (they said that they remembered to do their exercise anyway), while the other two rated the reminders to be of little importance or rather important.

\section{Primary effect outcomes}

No significant differences were found for pain-related disability and morale between the groups or in either of the groups at any of the follow-ups (see Table 5).

\section{Secondary effect outcomes}

There was a significant difference between the experimental and the comparison group for the CAT subscale $(P<0.001)$ between follow-up 1 and 2, which showed a higher degree of catastrophizing thoughts in the experimental group. No other significant differences between groups were found (see Table 5).

In the experimental group, there were significant increases in degree of self-efficacy for exercise $(P<0.05)$ and level of physical activity $(P<0.05)$, as well as slower gait speed $(P<0.05)$ at follow-up 1 compared to baseline. Also, significantly higher concerns for falling $(P<0.05)$

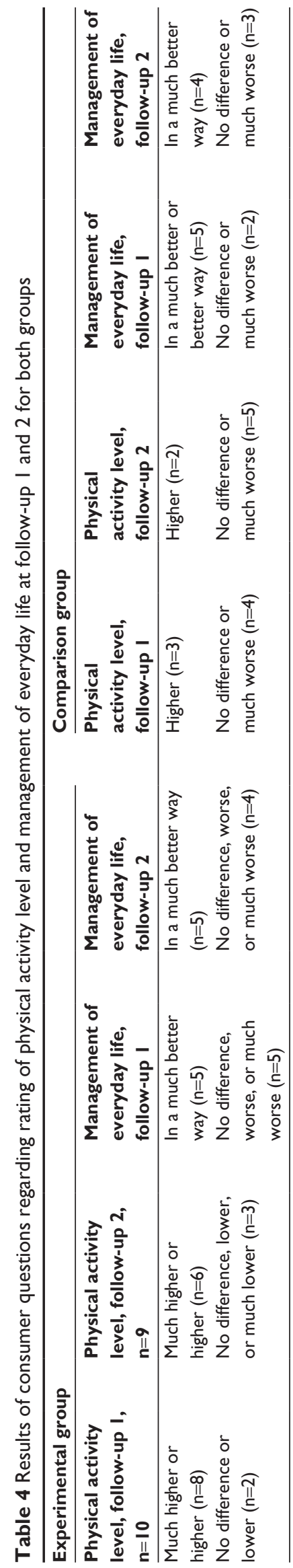




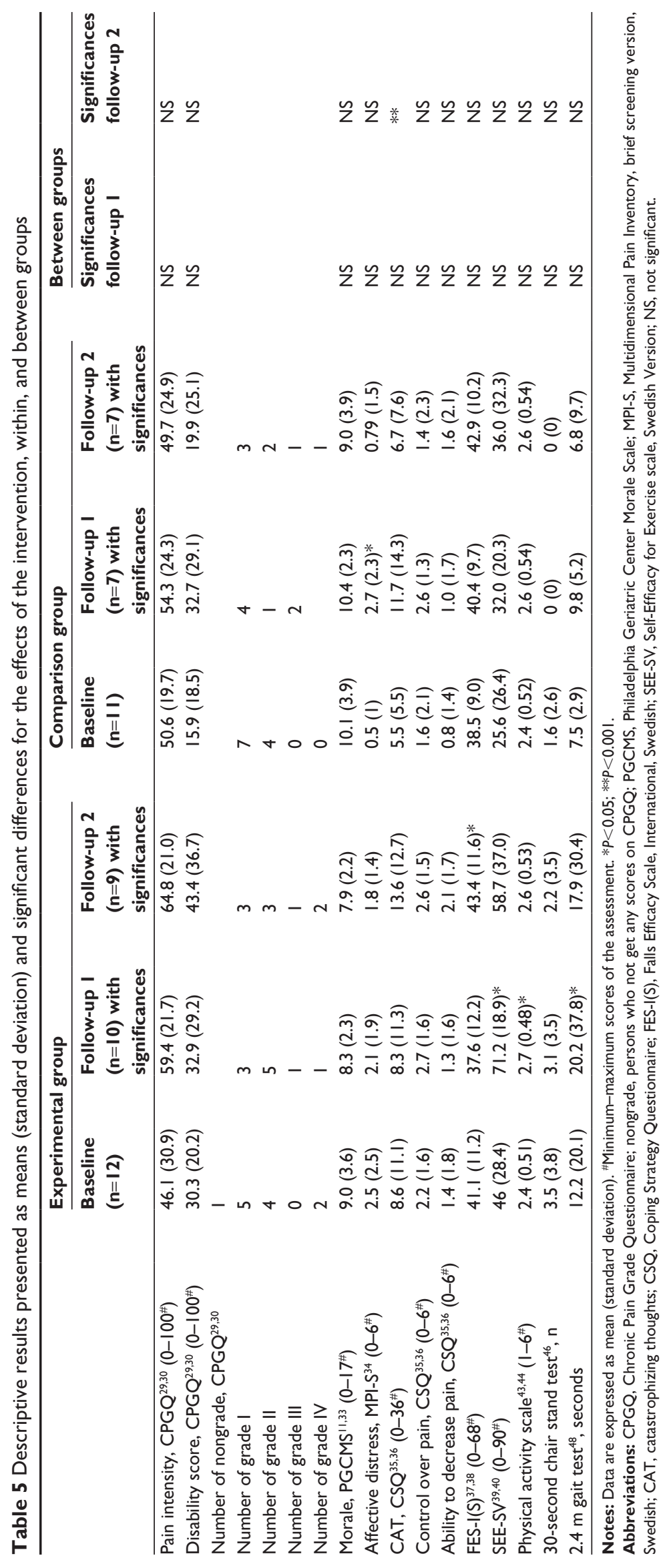


at follow-up 2 compared to follow-up 1 were found in the experimental group. In the comparison group, there was a significant increase in affective distress $(P<0.05)$, at follow-up 1 compared to baseline.

\section{Discussion}

Feasibility studies play a key role in estimating important parameters that need special concern, and should be carefully designed when planning and conducting a larger study. ${ }^{26}$ The results from the present study contribute two main findings, which we consider to be of high clinical relevance and importance when planning future research in the field. Firstly, the results show that the behavioral medicine intervention in physical therapy, in relation to adherence to study procedure and intervention protocol, was capable of being conducted. Secondly, the results give a hint that this intervention may improve levels of physical activity and self-efficacy in exercise and capability to manage everyday life in a better way.

Willingness to participate was judged to be low because only $23(22 \%)$ of 104 eligible women agreed to participate in the study. Reasons to decline participation given by the women were health-related problems, lack of energy, and no perceived need for a behavioral change. It is well known that older persons often decline participation in research studies. ${ }^{51}$ The recruitment in the present study was enhanced by contacting all the women via both letter and telephone. Using telephone contact has been shown to improve recruitment of older adults into research projects. ${ }^{52}$ A major problem for the target group was that they were not able to get outdoors by themselves, and they probably would have had problems participating in a study at a clinic. The fact that the study was home-based may have improved the willingness to participate in the study. However, in our study the willingness to participate was low even though the study was home-based.

In total, seven women (30\%) dropped out during the study period, five of whom for health-related reasons, which is a well-known problem when doing research that involves older people. ${ }^{51}$ The dropout rate is concerning due to the risk of possible bias. ${ }^{53}$ Strategies that can optimize the retention rate in clinical trials involving older adults with various chronic illnesses are to maintain excellent communication, listen to the participants' needs, and hire dedicated staff. ${ }^{54}$ We used some of the suggested strategies in this study, such as always calling the participant 1 hour before the appointment for the visit (excellent communication) and letting the participant decide day and time for the visits (listening to participants' needs). Nevertheless, these different strategies can be refined and developed in future studies. An example from this study is that we might have prevented one dropout if we could have offered help with filling out activity diaries.

Achieving behavioral change is not easy, and is associated with complexity among older adults, eg, disabilities and diseases, cognitive decline, and lack of available support. ${ }^{24}$ Behavioral change depends partly on available support, ${ }^{24}$ and unfortunately the reminders of home-help staff did not work out as planned in the present study. On the other hand, the results showed that the reminders were not perceived as positive support by the women. It is possible that the participants may not have really understood the purpose of the reminder, which was to reinforce behavioral changes. An ethical aspect is that the person reminding may be perceived as intrusive, and the women may also have felt monitored by the staff. Furthermore, the women may have felt less independent when reminded of something that they actually could do by themselves. When conducting a larger study, the type of reminder or the way to be reminded should be chosen by the participant.

Another support to improve behavioral changes is the use of activity diaries, which also enables checking for adherence to the intervention. ${ }^{16}$ Three of the participants, one of whom was a dropout, had problems filling out the activity diary. In future studies, there is a need for offering support to those who cannot fill out the diaries by themselves. However, being dependent on someone else to fill out the diaries may be associated with issues, eg, that the diary may not function as a support in the same way for behavior change, word choices may be affected, or participants may feel less involved or engaged in the study than if they could fill out the diary by themselves. Also, activity diaries that are adapted to older persons need to be created. An alternative or complement to activity diaries in the present study could have been the use of accelerometers, which give an objective measurement of the level of physical activity, but are not a panacea for physical activity assessment. ${ }^{55}$

The results imply that behavioral medicine physical therapy interventions may increase levels of physical activity. Increasing physical activity levels is of high interest, since previous research has shown that older adults living with chronic pain are less physically active than those without pain. ${ }^{23}$ Manor and Lipsitz ${ }^{56}$ discuss in their study how benefits of being physically active for older persons can be optimized by using exercises with a focus on functional daily 
tasks/activities. These authors' description of intervention strategy is in line with the behavioral medicine intervention in physical therapy in the present study. A limitation was that we could not analyze at what level of intensity the women exercised according to the recommendations. Even though we have no data regarding intensity, the results indicate that the level of physical activity may have been improved for the women in the experimental group. The results also imply that self-efficacy for exercise may have been improved for the women in the experimental group. These results are in line with previous research where self-efficacy has been shown to enhance performance of physical activity. ${ }^{57}$

To reduce the risk of injuries from falls, communitydwelling older adults who are at risk of falls, eg, older persons with chronic pain, ${ }^{58}$ should perform exercises that maintain or improve their balance. ${ }^{27} \mathrm{With}$ regard to balance exercises, it was found to be a problem to perform these types of exercises at the participant's individual level. This might be explained by a lack of physical support by another person to ensure that the exercises were safe to perform. To achieve maximum effect of the balance training, it should be done at the limit of the person's capacity and challenging postural stability, but still be performed safely. ${ }^{59}$ In a future study, physical support from another person, eg, home-help services, may be required to optimize the effect of balance training.

A reasonable assumption regarding the issue to find a goal behavior may concern lack of self-efficacy to perform everyday activities. The women in this study seemed to think that they were not able to do their everyday activities in another way or that they could gain better ability in everyday activities and become more independent. The study results imply that the women in both groups felt able to manage their everyday life in a better way, and it may be assumed that self-efficacy was a contributing factor to these results. Previous research has shown that self-efficacy is of importance to reduce functional decline in older adults with chronic diseases. ${ }^{60}$ Self-efficacy is also a crucial factor in the development of pain-related disability and beliefs. ${ }^{6}$ Therefore, it is of high importance that health care professionals have knowledge about and can inform, encourage, and enable self-efficacy for this specific population in their everyday life, with the goal of reducing pain-related disability and beliefs. ${ }^{13,61,62}$ This topic is of high interest for future research.

The study did not show any effects of the intervention on the primary effect outcomes. Due to the lack of intervention studies in similar populations, it was difficult to find comparable studies. However, previous research in primary care patients has shown positive effects on pain intensity, using the CPGQ as outcome measurement, ${ }^{62}$ and physical exercise may reduce participation restriction for older adults who are having difficulty coping with pain. ${ }^{22}$ Even if this study did not show any effects on morale, previous research implies short-term effects on morale through exercise as a single intervention for older adults living in residential care facilities. ${ }^{63}$ It is of high importance that larger studies will be done to evaluate and find interventions that can reduce painrelated disability and improve morale for the target group.

The participants in the comparison group reported during the intervention an increase in affective distress, while participants in the experimental group reported higher self-efficacy for exercise and levels of catastrophizing thoughts, as well as slower gait speed. A common problem when doing research among older adults is that their health status is fluctuating, and this can have a negative effect on the results, ${ }^{51}$ but a fluctuating health state can also hide potential effects of the intervention. This may be the explanation for the lack of results in this study.

In light of these results and the knowledge that pain is a complex and multidimensional experience, further research needs to be conducted in larger studies to evaluate the effects of a behavioral medicine intervention in physical therapy. The overall goal is to identify interventions that maintain and improve independency and assure high quality of life for older women living alone at home, who are living with chronic pain and dependent on formal care to manage their everyday life.

\section{Limitations and strengths}

The results from this study are encouraging regarding feasibility, but the effects should be interpreted with caution. Firstly, the small sample size may be a cause for the nonsignificant results in the primary effect outcomes in the study. Therefore, there is a risk for type 1 and 2 error in the study. ${ }^{63}$ However, the sample size and participation rate were in line with previous pilot studies or even higher. ${ }^{64,65}$

We are aware that some of the assessments have not been used in the older population to a great extent before, and thus the validity and reliability of the assessments can be a source of bias. However, the Cronbach's $\alpha$ scores showed that the internal consistency of these assessments was satisfactory. The chosen assessments in the study were the best available at the time. Further studies are 
needed to enable investigation of reliability and validity on assessments, and larger studies are needed before the effect of the intervention can be generalized to the target population.

A strength with this feasibility study was the use of a randomized trial with a two-group design and with two follow-up measurements. This will facilitate the use of the results in a larger trial and for calculations of power for an optimal sample size.

A weakness according to the evaluation of the study was that no external physical therapist was involved to perform the assessments or the intervention. We are aware that the fact that the first author did all assessments as well as the intervention might have affected the results of the study. In future studies, we strongly recommend the involvement of external physical therapists who are blinded to the participants' group allocation. ${ }^{66}$

The limitations that were found regarding the study procedure and intervention protocol were identified, and possible solutions to these difficulties were suggested. These suggestions could help improve the design of a larger study.

\section{Conclusion}

The present study demonstrates that an individualized behavioral medicine intervention in physical therapy for older women, living alone with chronic pain and dependent on formal care, was capable of being conducted, but study procedure and intervention have to be refined and tested in a larger feasibility study. The results imply that the behavioral intervention improved levels of physical activity and self-efficacy for exercise. The results also indicate that the majority of the women felt able to manage everyday life in a better way.

The study highlights the importance of further research to evaluate the effects of behavioral medicine interventions in physical therapy, with the goal of reducing pain-related disability and pain-related beliefs and improving morale, as well as improving self-efficacy in relation to everyday activities/everyday life. Further studies are also needed to evaluate the benefit and effects of individualized reminder routines, support in collecting self-report data, safety procedures for balance training, and training of personnel to enhance self-efficacy.

\section{Acknowledgments}

We sincerely thank all the women and the home-help service staff who participated in the study. This study was supported by Mälardalen University and the Ragnhild and Einar Lundström Memorial Foundation.

\section{Disclosure}

The authors report no conflicts of interest in this work.

\section{References}

1. Jakobsson U, Rahm Hallberg I, Westergren A. Pain management in elderly persons who require assistance with activities of daily living: a comparison of those living at home with those in special accommodations. Eur J Pain. 2004;8(4):335-344.

2. Kharicha K, Iliffe S, Harari D, Swift C, Gillmann G, Stuck AE. Health risk appraisal in older people 1: are older people living alone an 'at-risk' group? Br J Gen Pract. 2007;57(537):271-276.

3. Jakobsson U, Hallberg IR, Westergren A. Overall and health related quality of life among the oldest old in pain. Qual Life Res. 2004;13(1): $125-136$.

4. Gibson SJ, Lussier D. Prevalence and relevance of pain in older persons. Pain Med. 2012;13 Supp1 2:S23-S26.

5. Keefe FJ, Lefebvre JC, Egert JR, Affleck G, Sullivan MJ, Caldwell DS. The relationship of gender to pain, pain behavior, and disability in osteoarthritis patients: the role of catastrophizing. Pain. 2000;87(3): 325-334.

6. Denison E, Asenlöf P, Lindberg P. Self-efficacy, fear avoidance, and pain intensity as predictors of disability in subacute and chronic musculoskeletal pain patients in primary health care. Pain. 2004; 111(3):245-252.

7. Baranowski T, Perry CL, Parcel GS. How individuals, environments, and health behavior interact. In: Glanz K, Lewis FM, Rimer BK, editors. Health Behavior and Health Education: Theory, Research, and Practice. 3rd ed. San Francisco: Jossey-Bass; 2002:165-184.

8. Bandura A. Self-efficacy: toward a unifying theory of behavioral change. Psychol Rev. 1977;84(2):191-215.

9. Cederbom S, Söderlund A, Denison E, von Heideken Wågert P. Chronic pain among older women living alone. A study focusing on disability and morale. Eur J Physiother. Epub 2014 Mar 26.

10. Niklasson J, Lövheim H, Gustafson Y. Morale in very old people who have had a stroke. Arch Gerontol Geriatr. 2014;58(3):408-414.

11. Lawton MP. The dimension of morale. In: Kent DP, Kastenbaum R, Sherwood S, editors. Research Planning and Action for the Elderly: The Power and Potential of Social Science. New York: Behavioral Publications; 1972:144-165.

12. von Heideken Wågert $\mathrm{P}$, Rönnmark $\mathrm{B}$, Rosendahl $\mathrm{E}$, et al. Morale in the oldest old: the Umeå 85+ study. Age Ageing. 2005;34(3):249-255.

13. Brown ST, Kirkpatrick MK, Swanson MS, McKenzie IL. Pain experience of the elderly. Pain Manag Nurs. 2011;12(4):190-196.

14. Minner D, Dorman Marek K. Evidence-based assessment and treatment of persistent pain in the community-dwelling elderly receiving home health services: a pathway. Home Health Care Manag Pract. 2005; 17(4):293-301.

15. Sandborgh M, Lindberg P, Åsenlöf P, Denison E. Implementing behavioral medicine in physiotherapy treatment. Part I: Clinical trial. Adv Physiother. 2010;12(1):2-12.

16. Denison E, Åsenlöf P. Behavioral Medicine Applications in Physiotherapy. Lund, Sweden: Studentlitteratur; 2012.

17. Åsenlöf P, Denison E, Lindberg P. Individually tailored treatment targeting activity, motor behavior, and cognition reduces pain-related disability: a randomized controlled trial in patients with musculoskeletal pain. J Pain. 2005;6(9):588-603.

18. Söderlund A, Lindberg P. Cognitive behavioural components in physiotherapy management of chronic whiplash associated disorders (WAD)-a randomised group study. G Ital Med Lav Ergon. 2007;29(1 Suppl A): A5-A11. 
19. SBU - Swedish Council on Health Technology Assessment. Rehabilitation in Chronic Pain: A Systematic Literature Review. Stockholm: SBU; 2010.

20. Gatchel RJ, Peng YB, Peters ML, Fuchs PN, Turk DC. The biopsychosocial approach to chronic pain: scientific advances and future directions. Psychol Bull. 2007;133(4):581-624.

21. AGS Panel on Persistent Pain in Older Persons. The management of persistent pain in older persons. J Am Geriatr Soc. 2002;50(6 Suppl): S205-S224.

22. Thomas E, Peat G, Harris L, Wilkie R, Croft PR. The prevalence of pain and pain interference in a general population of older adults: crosssectional findings from the North Staffordshire Osteoarthritis Project (NorStOP). Pain. 2004;110(1):361-368.

23. Stubbs B, Binnekade TT, Soundy A, Schofield P, Huijnen IP, Eggermont LH. Are older adults with chronic musculoskeletal pain less active than older adults without pain? A systematic review and meta-analysis. Pain Med. 2013;14(9):1316-1331.

24. Brawley LR, Rejeski WJ, King AC. Promoting physical activity for older adults: the challenges for changing behavior. Am Prev Med. 2003; 25(3):172-183.

25. Folstein MF, Folstein SE, McHugh PR. "Mini-mental state". A practical method for grading the cognitive state of patients for the clinician. J Psychiatr Res. 1975;12(3):189-198.

26. Lancaster GA, Dodd S, Williamson PR. Design and analysis of pilot studies: recommendations for good practice. J Eval Clin Pract. 2004; 10(2):307-312.

27. Nelson ME, Rejeski W, Blair SN, et al. Physical activity and public health in older adults: recommendation from the American College of Sports Medicine and the American Heart Association. Med Sci Sports Exerc. 2007;39(8):1435-1445.

28. World Health Organization. Global Recommendations on Physical Activity for Health. Geneva: WHO; 2010.

29. Skillgate E, Vingård E, Alfredsson L. Naprapathic manual therapy or evidence-based care for back and neck pain: a randomized, controlled trial. Clin J Pain. 2007;23(5):431-439.

30. Von Korff M, Dworkin SF, Le Resche L. Graded chronic pain status: an epidemiologic evaluation. Pain. 1990;40(3):279-291.

31. Smith BH, Penny KI, Purves AM, et al. The Chronic Pain Grade questionnaire: validation and reliability in postal research. Pain. 1997; 71(2):141-147.

32. Schmidt CO, Raspe H, Kohlmann T. Graded back pain revisited - do latent variable models change our understanding of severe back pain in the general population? Pain. 2010;149(1):50-56.

33. von Heideken Wågert $P$, Gustavsson JM, Lundin-Olsson L, et al. Health status in the oldest old. Age and sex differences in the Umeå 85+ study. Aging Clin Exp Res. 2006;18(2):116-126.

34. Jakobsson U, Horstmann V. Psychometric evaluation of multidimensional pain inventory (Swedish version) in a sample of elderly people. Eur J Pain. 2006;10(7):645-651.

35. Jensen I, Linton S. Coping Strategies Questionnaire (CSQ): reliability of the Swedish version of the CSQ. Scand J Behav Ther. 1993;22:139-145.

36. Stewart MW, Harvey ST, Evans IM. Coping and catastrophizing in chronic pain: a psychometric analysis and comparison of two measures. J Clin Psychol. 2001;57(1):131-138.

37. Kempen GI, Todd CJ, Van Haastregt JC, et al. Cross-cultural validation of the Falls Efficacy Scale International (FES-I) in older people: results from Germany, the Netherlands and the UK were satisfactory. Disabil Rehabil. 2007;29(2):155-162.

38. Nordell E, Andreasson M, Gall K, Thorngren KG. Evaluating the Swedish version of the Falls Efficacy Scale-International (FES-I). $A d v$ Physiother. 2009;11(2):81-87.

39. Resnick B, Jenkins LS. Testing the reliability and validity of the SelfEfficacy for Exercise scale. Nurs Res. 2000;49(3):154-159.

40. Cavrak A. Test of the Psychometric Properties of the Swedish Version of the Self-Efficacy for Exercise Scale for Patients in Cardiac Rehabilitation [master's thesis]. Gothenberg: University of Gothenberg; 2010.
41. Rydwik E, Hovmöller F, Boström C. Aspects of reliability and validity of the Swedish version of the Self-Efficacy for Exercise Scale for older people. Physiother Theory Pract. 2014;30(2):131-137.

42. Mosallanezhad Z, Hörder H, Salavati M, Nilsson-Wikmar L, Frändin K. Physical activity and physical functioning in Swedish and Iranian 75-yearolds - a comparison. Arch Gerontol Ger. 2012;55(2):422-430.

43. Mattiasson-Nilo I, Sonn U, Johannesson K, Gosman-Hedström G, Persson G, Grimby G. Domestic activities and walking in the elderly: evaluation from a 30-hour heart rate recording. Aging (Milano). 1990; 2(2):191-198.

44. Frändin K, Grimby G. Assessment of physical activity, fitness and performance in 76-year-olds. Scand J Med Sci Sports. 1994;4(1):41-46.

45. McCarthy EK, Horvat MA, Holtsberg PA, Wisenbaker JM. Repeated chair stands as a measure of lower limb strength in sexagenarian women. J Gerontol A Biologl Sci Med Sci. 2004;59(11):1207-1212.

46. Jones CJ, Rikli RE, Beam WC. A 30-s chair-stand test as a measure of lower body strength in community-residing older adults. Nurs Res. 2000;49(3):154-159.

47. Rydwik E, Bergland A, Forsén L, Frändin K. Investigation into the reliability and validity of the measurement of elderly people's clinical walking speed: a systematic review. Physiother Theory Pract. 2012; 28(3):238-256.

48. Guralnik JM, Simonsick EM, Ferrucci L, et al. A short physical performance battery assessing lower extremity function: association with self-reported disability and prediction of mortality and nursing home admission. J Gerontol. 1994;49(2):M85-M94.

49. Borg G. Borg's Perceived Exertion and Pain Scales. Champaign (IL): Human Kinetics; 1998.

50. Farrar JT, Young JP Jr, LaMoreaux L, Werth JL, Poole RM. Clinical importance of changes in chronic pain intensity measured on an 11-point numerical pain rating scale. Pain. 2001;94(2):149-158.

51. McMurdo ME, Roberts H, Parker S, et al. Improving recruitment of older people to research through good practice. Age Ageing. 2011;40(6): 659-665.

52. Harris TJ, Carey IM, Victor CR, Adams R, Cook DG. Optimising recruitment into a study of physical activity in older people: a randomised controlled trial of different approaches. Age Ageing. 2008; 37(6):659-665.

53. Dumville JC, Torgerson DJ, Hewitt CE. Research methods: reporting attrition in randomised controlled trials. BMJ. 2006;332(7547): 969-971.

54. Taylor-Piliae RE, Boros D, Coull BM. Strategies to improve recruitment and retention of older stroke survivors to a randomized clinical exercise trial. J Stroke and Cerebrovasc Dis. 2014;23(3):462-468.

55. Troiano RP, Berrigan D, Dodd KW, Mâsse LC, Tilert T, McDowell M. Physical activity in the United States measured by accelerometer. Med Sci Sports Exerc. 2008;40(1):181-188.

56. Manor B, Lipsitz LA. Physiologic complexity and aging: Implications for physical function and rehabilitation. Prog Neuropsychopharmacol Biol Psychiatry. 2013;45:287-293.

57. McAuley E, Blissmer B. Self-efficacy determinants and consequences of physical activity. Exerc Sport Sci Rev. 2000;28(2):85-88.

58. Leveille SG, Jones RN, Kiely DK, et al. Chronic musculoskeletal pain and the occurrence of falls in an older population. JAMA. 2009;302(20): 2214-2221.

59. Sherrington C, Whitney JC, Lord SR, Herbert RD, Cumming RG, Close JC. Effective exercise for the prevention of falls: a systematic review and meta-analysis. J Am Geriatr Soc. 2008;56(12):2234-2243.

60. Rejeski WJ, Miller ME, Foy C, Messier S, Rapp S. Self-efficacy and the progression of functional limitations and self-reported disability in older adults with knee pain. J Gerontol B Psychol Sci Soc Sci. 2001;56(5): S261-S265.

61. Covinsky KE, Palmer RM, Fortinsky RH, et al. Loss of independence in activities of daily living in older adults hospitalized with medical illnesses: increased vulnerability with age. J Am Geriatr Soc. 2003; 51(4):451-458 
62. Barry LC, Guo Z, Kerns RD, Duong BD, Reid MC. Functional selfefficacy and pain-related disability among older veterans with chronic pain in a primary care setting. Pain. 2003;104(1-2):131-137.

63. Tabachnick BG, Fidell LS. Using Multivariate Statistics. London: Pearson; 2013.

64. Pohl P, Dizdar N, Hallert E. The Ronnie Gardiner Rhythm and Music Method - a feasibility study in Parkinson's disease. Disabil Rehabil. 2013;35(26):2197-2204
65. Bieryla KA, Dold NM. Feasibility of Wii Fit training to improve clinical measures of balance in older adults. Clin Interv Aging. 2013; 8:775-781.

66. Boutron I, Moher D, Altman DG, Schulz KF, Ravaud P. Extending the CONSORT statement to randomized trials of nonpharmacologic treatment: explanation and elaboration. Ann Intern Med. 2008;148(4): 295-309.

\section{Publish your work in this journal}

Clinical Interventions in Aging is an international, peer-reviewed journal focusing on evidence-based reports on the value or lack thereof of treatments intended to prevent or delay the onset of maladaptive correlates of aging in human beings. This journal is indexed on PubMed Central, MedLine,

\section{Dovepress}

CAS, Scopus and the Elsevier Bibliographic databases. The manuscript management system is completely online and includes a very quick and fair peer-review system, which is all easy to use. Visit http://www.dovepress. $\mathrm{com} /$ testimonials.php to read real quotes from published authors. 